\title{
Application of Overfire Air Technology on an Example of a Steam Boiler PK-39 of the Aksu TPP (Kazakhstan)
}

\author{
A. Askarova, S. Bolegenova, V. Maximov, S.Bolegenova, Z. Gabitova, A. Yergaliyeva, A. \\ Nugymanova, M. Beketayeva, Sh. Ospanova
}

\begin{abstract}
When burning any fossil fuels, one of the most harmful combustion products are nitrogen oxides NOx, which damage both the environment and human health in particular. Reduction of NOx emissions from fuel combustion at TPPs plays an important role in reducing the total level of nitrogen oxides NOx emitted into the atmosphere. One way to reduce the concentration of nitrogen oxides NOx is the stepwise combustion of the pulverized coal mixture, in particular the "Overfire Air» technology. The essence of this method is that the main volume of air is fed into the pulverized burners, and the rest of the air is further along the height of the torch through special nozzles. Structurally, the method of stepwise combustion of fuel can be carried out in boilers with a two-tier arrangement of burners along the height of the combustion chamber. In this case, practically no significant reconstruction of the boiler is required, which is associated with additional costs. In the present work, computational experiments on the use of modern overfire air technology (OFA) in the combustion chamber of the PK-39 boiler of the Aksu TPP were carried out and the fields of the main characteristics of heat and mass transfer, as well as the influence of the mass flow of the oxidant through the OFA injectors on the combustion process were obtained.
\end{abstract}

Index Terms - coal combustion, numerical simulation, overfire air technology.

\section{INTRODUCTION}

A S OF TODAY Kazakhstan is one of the states possessing a huge stock of hydrocarbons, which render essential influence on formation and a condition of the world energy market [1-3].

A. ASKAROVA, is with Department of Science in Physics and Mathematics Al-Farabi Kazakh National University, (e-mail: Aliya.Askarova@kaznu.kz).

S. BOLEGENOVA, is with Dep. of Science in Physics and Mathematics AlFarabi Kazakh National University, (e-mail: Saltanat.Bolegenova@kaznu.kz). V. MAXIMOV, is with Department of Science in Physics and Mathematics Al-Farabi Kazakh National University, (e-mail: maximov.v@mail.ru).

S.BOLEGENOVA, is with Dep. of Science in Physics and Mathematics AlFarabi Kazakh National University, (e-mail : Symbat.80@mail.ru).

Z. GABITOVA, is with Department of Science in Physics and Mathematics Al-Farabi Kazakh National University, (e-mail: z.gabitova @kaznu.kz).

A. YERGALIYEVA is with Dep. of Science in Physics and Mathematics AlFarabi Kazakh National University, (e-mail: a.yergaliyeva@kaznu.kz).

A. NUGYMANOVA, is with Dep. of Science in Physics and Mathematics Al-Farabi Kazakh National University, (e-mail a.nugymanova@kaznu.kz).

M. BEKETAYEVA is with Dep. of Science in Physics and Mathematics AlFarabi Kazakh National University, (e-mail: m.beketayeva@kaznu.kz).

SH. OSPANOVA, is with Department of Science in Physics and Mathematics Al-Farabi Kazakh National University, (e-mail sh.ospanova@kaznu.kz).

Manuscript received May 14, 2018; accepted October 20, 2018

DOI: $10.17694 /$ bajece. 475543
In the Republic of Kazakhstan, about $80 \%$ of the country's energy supply comes from the production of electricity by 69 power plants, the main source of which is Kazakh coal [4-6].

The coal mining in Republic is carried out basically by the open way, which makes this type of solid fuel the cheapest, but low-grade (high ash content in its composition) in our country a source of energy [3,7-8]. At the same time, the coal of Kazakhstan possesses a number of advantages - small sulphur content of coals and a high volatiles content on a dry ash-free basis.

For the sustainable development of heat and power industry of the country in the near future, it is necessary to optimize the combustion of traditional energy fuel (Kazakh coal), to develop and implement clean energy technologies; to protect the environment from harmful dust and gas emissions and ensure the efficiency of power plants. One of the methods for reduction of NOx concentration is the overfire air technology - OFA.

Technological methods for suppressing the formation of nitrogen oxides are based on a reduction in the peak temperature and oxygen content in the active combustion zone, as well as in the formation in the combustion chamber of zones with a reducing medium, where the products of incomplete combustion, reacting with the formed nitric oxide, lead to the reduction of NOx to molecular nitrogen N2.

Thus, in the zone of active combustion, an oxygen-depleted and fuel-enriched combustion zone is formed. Due to the lack of air in this area, the average temperature is lower than in traditional combustion, which allows to reduce the amount of fuel and thermal nitrogen oxides. Further, above the level of the main burners, additional air is supplied through the tertiary air nozzles necessary for afterburning the products of incomplete combustion and an oxidizing medium is formed [9-10].

The most difficult step in realization of the OFA technology is to define the optimal location height and diameter of nozzles through which air will be supplied, and to find the best ratio of air supplying through the main burner and OFAinjectors. These characteristics depend on design of the boilers and the method of supplying fuel-air mixture [10-11].

To effectively implement this technology on an industrial boiler, the height of the OFA injectors should be chosen so that in the active combustion zone a complete burn-out of the fuel and its afterburning to the final combustion products are ensured, since incomplete mixing of fuel and oxidant can

"This article was presented during the International conference Alternative Energy Sources, Materials \& Technologies (AESMT'18), 14 - 15 May, 2018 in Plovdiv, Bulgaria" 
increase underburning [12].

\section{BASIC EQUATIONS OF HEAT AND MASS TRANSFER IN REACTIVE MEDIA}

The computational experiment was carried out on the basis of the solution of the three-dimensional equations of convective heat and mass transfer taking into account the propagation of heat, thermal radiation, chemical reactions, and the multiphase nature of the medium. To describe the threedimensional motion of reacting currents in the furnace chamber of the boiler PK-39, a system of differential equations [3,13-19] based on the control volume method [6, 18-20] is used:

- The conservation law of mass or the continuity equation

The ratio of the mass balance for control volume represents the continuity equation.

$$
\frac{\partial \rho}{\partial t}=-\frac{\partial\left(\rho u_{j}\right)}{\partial x_{j}}
$$

- The conservation law of momentum or equation of motion

Momentum balance is based on the second law of Newtonmomentum change of the liquid in the control volume is equal to the sum of all external (surface and efficient volume) forces attached to the control volume.

$$
\begin{aligned}
\frac{\partial\left(\rho u_{i}\right)}{\partial t}= & -\frac{\partial\left(\rho u_{i} u_{j}\right)}{\partial x_{j}}+\frac{\partial}{\partial x_{j}}\left[\mu\left(\frac{\partial u_{i}}{\partial x_{j}}\right)\right]-\frac{\partial p}{\partial x_{i}}+\rho f_{i}+ \\
& +\frac{\partial}{\partial x_{j}}\left[\mu\left(\frac{\partial u_{j}}{\partial x_{i}}-\frac{2}{3} \delta_{i j} \frac{\partial u_{l}}{\partial x_{j}}\right)\right] .
\end{aligned}
$$

\section{- $\quad$ The conservation law of energy}

The energy equation is based on the first law of thermodynamics.

$$
\frac{\partial(\rho h)}{\partial t}=-\frac{\partial\left(\rho u_{i} h\right)}{\partial x_{i}}+\frac{\partial}{\partial x_{i}}\left(\frac{\mu}{\operatorname{Pr}} \frac{\partial h}{\partial x_{i}}\right)+S_{h}
$$

- The conservation law of for the components of the substance

In an isotropic medium consisting of $\beta$ components, the components can move with different velocities $u_{i, \beta}$. For the mass balance of the $\beta$-component of the medium it can be written:

$$
\frac{\partial\left(\rho c_{\beta}\right)}{\partial t}=-\frac{\partial\left(\rho u_{i} c_{\beta}\right)}{\partial x_{i}}+\frac{\partial}{\partial x_{i}}\left[\rho D_{c_{\beta}} \frac{\partial c_{\beta}}{\partial x_{i}}\right]+S_{\beta} .
$$

The combustion of coal dust in combustion chambers is turbulent, and in this connection, a standard $k-\varepsilon$ model of turbulence was used to simulate turbulent viscosity and closure of the system $[1,2,6,15]$. The model includes

- The equation of transport of turbulent kinetic energy $k$ :

$$
\frac{\partial(\rho k)}{\partial t}=-\frac{\partial\left(\rho u_{j} k\right)}{\partial x_{j}}+\frac{\partial}{\partial x_{j}}\left[\frac{\mu_{e f f}}{\sigma_{k}} \frac{\partial k}{\partial x_{j}}\right]+P-\rho \cdot \varepsilon,
$$

where $\mathrm{P}$ - turbulent kinetic energy production:

$$
P=\left[\mu_{t u r b}\left(\frac{\partial u_{j}}{\partial x_{j}}+\frac{\partial u_{j}}{\partial x_{i}}\right)-\frac{2}{3} \rho k \delta_{i j}\right] \frac{\partial u_{j}}{\partial x_{j}}
$$

The equation of dissipation of turbulent kinetic energy $\varepsilon$ :

$$
\frac{\partial(\rho \varepsilon)}{\partial t}=-\frac{\partial\left(\rho u_{j} \varepsilon\right)}{\partial x_{j}}+\frac{\partial}{\partial x_{j}}\left[\frac{\mu_{e f f}}{\sigma_{\varepsilon}} \frac{\partial \varepsilon}{\partial x_{j}}\right]+C_{\varepsilon, 1} \cdot \frac{\varepsilon}{k} \cdot P-C_{\varepsilon, 2} \cdot \frac{\varepsilon^{2}}{k} \cdot \rho,
$$

where $\rho \varepsilon$ - transformation of the kinetic energy of the pulsating motion into internal energy (dissipation);

$\sigma_{k}, \sigma_{\varepsilon}$ - the corresponding turbulent Prandtl numbers.

Considering the processes of heat exchange in technical reacting flows in combustion chambers, heat exchange by means of radiation makes the greatest contribution to total heat transfer. In the flame zone, the contribution of radiant heat exchange is up to $90 \%$ of the total heat transfer and even more [21]. In this regard, the simulation of heat transfer through radiation in reacting flows in combustion chambers is one of the most important stages in the calculation of heat transfer processes in real combustion chambers.

At the calculations connected with radiant heat exchange, the characteristic values are the radiation energy $E$ and the spectral intensity $I v$. To describe the change in the magnitude of the spectral intensity in time, an infinitesimal volume is allocated in the investigated space, with an area $d A$ and a length $d s$, in which emission, absorption and scattering of electromagnetic radiation quanta occur.

Thus, the change in the radiation intensity I $v$ along the infinitesimal volume can be written in the form of the energy balance equation (8):

$$
\begin{gathered}
\frac{1}{c} \cdot \frac{\partial I_{v}}{\partial t}+\frac{\partial I_{v}}{\partial s}=-\left(K_{a b s, v}+K_{s c a, v}\right) \cdot I_{v}+K_{a b s, v} \cdot I_{v}+ \\
+\frac{K_{s c a, v}}{4 \pi} \times \int_{4 \pi}\left(P\left(\Omega_{i} \rightarrow \Omega\right) \cdot I_{v}\left(\Omega_{i}\right)\right) d \Omega_{i}
\end{gathered}
$$

In connection with the fact that the change in the radiation intensity in time is much less than the speed of light, the first term in the equation of the balance of radiant energy can be neglected. Due to the fact that the system is in thermodynamic equilibrium and the temperature of the radiant energy of the bodies radiated and absorbed is the same, then we can assume that the absorption and radiation coefficients are equal. In addition, in the paper all the bodies participating in heat transfer by radiation are represented as gray radiators.

Thus, the expression (8) can be written as [15,22]:

$$
\begin{aligned}
& \frac{\partial I_{v}}{\partial s}=-\left(K_{a b s}+K_{s c a}\right) I_{v}+K_{a b s} \frac{\sigma}{\pi} T^{4}+ \\
& +\frac{K_{s c a}}{4 \pi} \times \int_{4 \pi}\left(P\left(\Omega_{i} \rightarrow \Omega\right) \cdot I_{v}\left(\Omega_{i}\right)\right) d \Omega_{i}
\end{aligned}
$$

For calculation of heat exchange by radiation in furnace chamber the model of a stream was used, according to which Eq. (9) is integrated over solid angles, for which flows are assumed to be independent of direction.

\section{PHYSICAL AND GEOMETRICAL MODEL OF THE PK-39 BOILER}

To solve the systems of differential equations describing the processes of heat and mass transfer in the combustion chamber of the boiler PK-39 of Aksu TPP, the control volume method $[6,18-20]$ was used.

The essence of the method is that the space of the combustion chamber is divided into control volumes and for each point of space surrounded by a certain volume, the 
equations of conservation of physical quantity (mass, momentum, energy, etc.) are solved.

Before the numerical experiments using the PREPROZ program [22], files and startup programs were created for two investigated cases, including initial and boundary conditions, the characteristics of the fuel (elemental composition, heat of combustion, fractional composition of Ekibastuz coal), the geometry of the boiler and burner devices [6,13,23]. The main characteristics of the combustion chamber of the boiler PK-39 of Aksu TPP and burnt Ekibastuz coal are presented in table 1.

TABLE I

CHARACTERISTICS OF THE COMBUSTION CHAMBER OF THE BOILER PK-39 OF AKSU TPP AND THE PULVERIZED COAL BURNED ON IT (EKIBASTUZ COAL) [3]

\begin{tabular}{|c|c|c|}
\hline $\begin{array}{l}\text { The name of the characteristics, } \\
\text { dimensionality }\end{array}$ & Designation & Value \\
\hline Fuel consumption per boiler, $\mathrm{kg} / \mathrm{h}$ & B & 87500 \\
\hline Fuel consumption per burner, $\mathrm{kg} / \mathrm{h}$ & $\mathrm{B}^{\mathrm{B}}=\mathrm{B} / \mathrm{Z}$ & 7291.1 \\
\hline \multirow{7}{*}{$\begin{array}{l}\text { Fuel - Ekibastuz coal } \\
\text { Composition of coal, } \%\end{array}$} & $\mathrm{~W}^{\mathrm{p}}$ & 7.0 \\
\hline & $\mathrm{A}^{\mathrm{p}}$ & 40.9 \\
\hline & $\mathrm{S}^{\mathrm{p}}$ & 0.8 \\
\hline & $\mathrm{Cp}^{\mathrm{p}}$ & 41.1 \\
\hline & $\mathrm{H}^{\mathrm{p}}$ & 2.8 \\
\hline & $\mathrm{O}^{\mathrm{p}}$ & 6.6 \\
\hline & $\mathrm{N}^{\mathrm{p}}$ & 0.8 \\
\hline Calorific value, $\mathrm{MJ} / \mathrm{kg}$ & $\mathrm{Q}_{\mathrm{H}}^{\mathrm{p}}$ & 15.87 \\
\hline Volatile, $\%$ & $\mathrm{~V}^{\mathrm{F}}$ & 30.0 \\
\hline $\begin{array}{l}\text { Coefficient of excess air at the exit } \\
\text { from the furnace }\end{array}$ & $\alpha \mathrm{T}$ & 1.25 \\
\hline Coefficient of excess air in the burners & $\alpha \Gamma$ & 1.15 \\
\hline Temperature of the air mixture, ${ }^{\circ} \mathrm{C}(\mathrm{K})$ & $\mathrm{T}_{\mathrm{a}}$ & $150(423)$ \\
\hline Temperature of secondary air, ${ }^{\circ} \mathrm{C}(\mathrm{K})$ & $\mathrm{T}_{2}$ & $327(600)$ \\
\hline Type of burners & \multicolumn{2}{|c|}{ Vortex } \\
\hline Number of burners, pcs & $\mathrm{n}_{\mathrm{B}}$ & 12 \\
\hline Height of the furnace, $\mathrm{m}$ & $\mathrm{z}(\mathrm{H})$ & 29.985 \\
\hline Width of the furnace, $\mathrm{m}$ & $\mathrm{Y}$ & 10.76 \\
\hline Depth of the furnace, $m$ & $\mathrm{X}$ & 7.762 \\
\hline
\end{tabular}

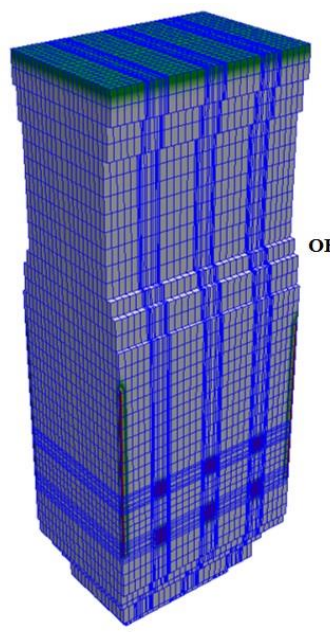

a)

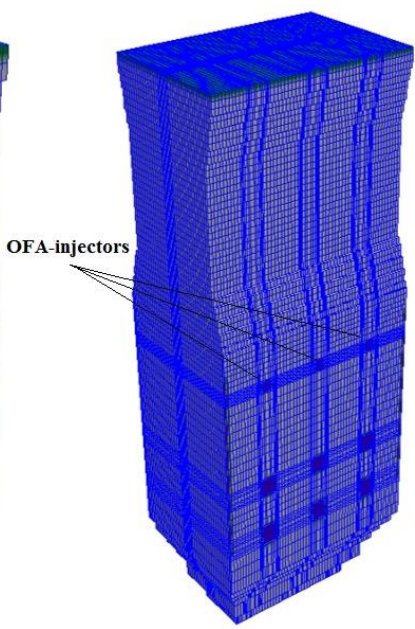

b)
Fig. 1. General view and a gridding of the PK-39boiler
CONSTRUCTIONAL CHARACTERISTICS OF A BOILER PK-39 OF AKSU TPP AT THE ORGANIZATION OF STAGED COMBUSTION OF FUEL

\begin{tabular}{|l|c|}
\hline \multicolumn{1}{|c|}{ The characteristic } & Value \\
\hline Number of OFA-nozzles, pcs & 6 \\
\hline The height of the tier of the lower burners, $\mathrm{m}$ & 7,315 \\
\hline The height of the tier of the upper burners, $\mathrm{m}$ & 10,115 \\
\hline The height of the tier of the OFA-nozzles, $\mathrm{m}$ & 15,735 \\
\hline Diameter of OFA-nozzles, $\mathrm{m}$ & 0,7 \\
\hline
\end{tabular}

Fig. 1 provides a general view and a gridding of the boiler: for traditional pulverized coal combustion (Fig. 1a), at implement of secondary air nozzles - OFA (Fig. 1b). The major structural characteristics are presented in table 2 . In the work, cases with a percentage of the supply air through the nozzles OFA equal to 0 (base case), 10 and $20 \%$ of the total amount of secondary and tertiary air supplied to the combustion chamber.

\section{RESULTS AND DISCUSSION}

Results of researches obtained with the FLOREAN software package [25-30] are presented below in the paper. Fig. 2 shows the distribution of the full-velocity vector in different sections of the combustion chamber for the base case (OFA 0\%) and with the use of the overfire air technology (OFA 20\%). Analysis of the figures shows that with the use of OFA technology, the combustion process in the central part of the combustion chamber is more intense compared to the base case.
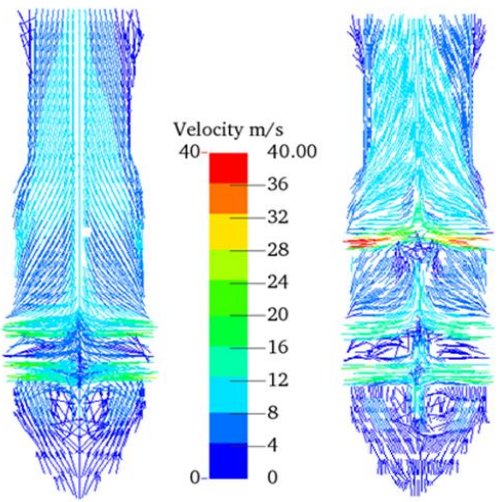

a)
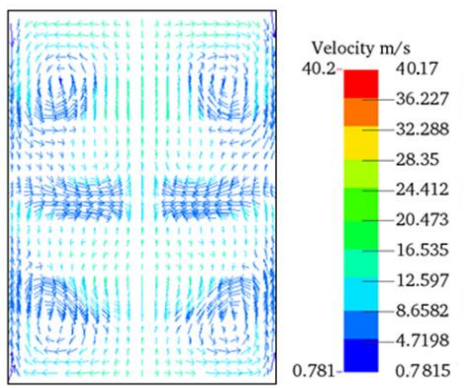

b)

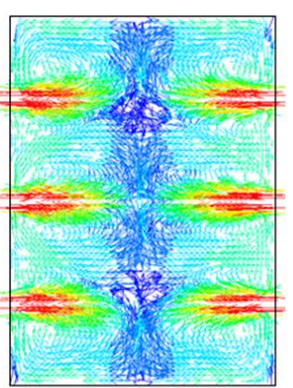

TABLE II 

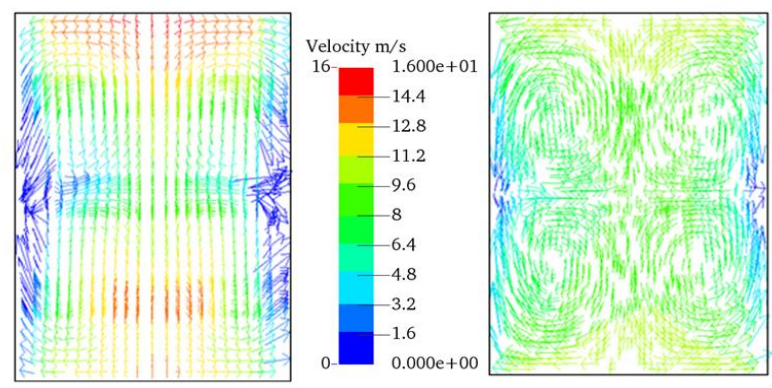

c)

Fig.2. The distribution of the velocity vector in different sections of the combustion chamber a) the central longitudinal section $(\mathrm{Y}=5.38 \mathrm{~m})$; b) the cross-sectional area of the OFA-nozzles $(\mathrm{Z}=15.735 \mathrm{~m})$; c) cross-section at the outlet from the combustion chamber of the boiler PK-39 (Z=29,595 m)

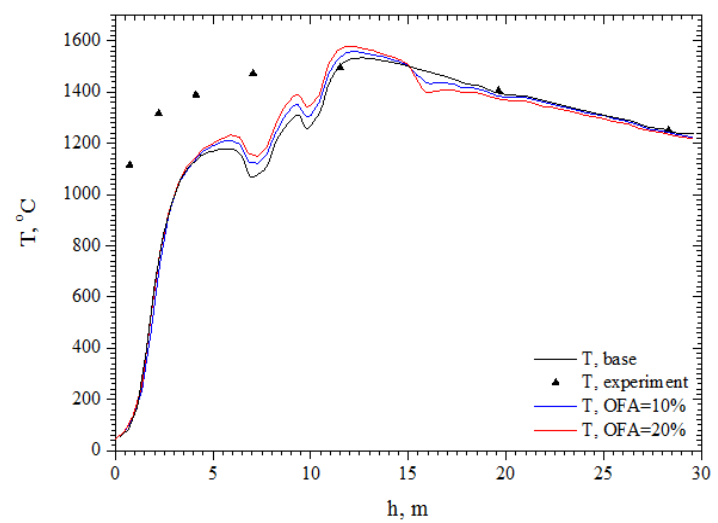

Fig.3. Temperature distribution over the height of the combustion chamber of the boiler PK-39 for different values of air supplied through the nozzles OFA and comparison with experiment [24]

Fig. 3 shows the distribution of average temperatures on height of furnace chamber for the investigated cases. The results of full-scale experiment conducted at Aksu TPP [24] are also plotted on the graph. Moving towards the exit of the furnace temperature field is equalized and differences in temperature values for different occasions decrease.

Also, it can be seen that the greatest differences between the results of computational and full-scale experiments are observed in the area of ignition of the pulverized coal mixture. Moving towards the exit from the furnace space, these differences are insignificant, which indicates good consistency and, as a consequence, the adequacy of the used models.

Fig. 4-5 show graphs of the distribution of combustion products - carbon $\mathrm{CO}_{2}$ and nitrogen $\mathrm{NO}$ oxides along the height of furnace chamber of PK-39 boiler of Aksu TPP. Analyzing the distribution of carbon monoxide (Fig. 4), it can be seen that the greatest differences in the values are noticeable in the area of the burner belt and OFA-injectors. To the exit from the combustion chamber with increasing mass flow of air through the OFA-nozzles, the concentration of carbon dioxide $\mathrm{CO}_{2}$ is reduced.

Fig. 5 represents the distribution of the concentration of nitrogen oxide NO along the height of furnace chamber of PK39 boiler of Aksu TPP.

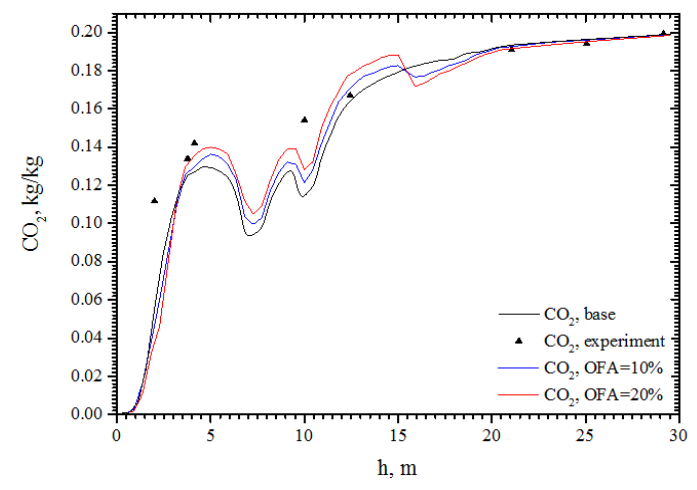

Fig.4. Distribution of $\mathrm{CO}_{2}$ concentration along the furnace chamber height for different values of air supplied through the nozzles OFA and comparison with experiment [24].

Analysis of Fig. 5 allows us to conclude that an increase in the mass flow of air supplied through OFA injectors leads to a decrease in NO concentration at the outlet from the furnace chamber of PK-39 boiler of Aksu TPP. This is confirmed by the known dependence of $\mathrm{NO}$ oxides formed on temperature [31] and analysis of the temperature distribution in the combustion chamber of the boiler PK-39, presented in Fig. 3.

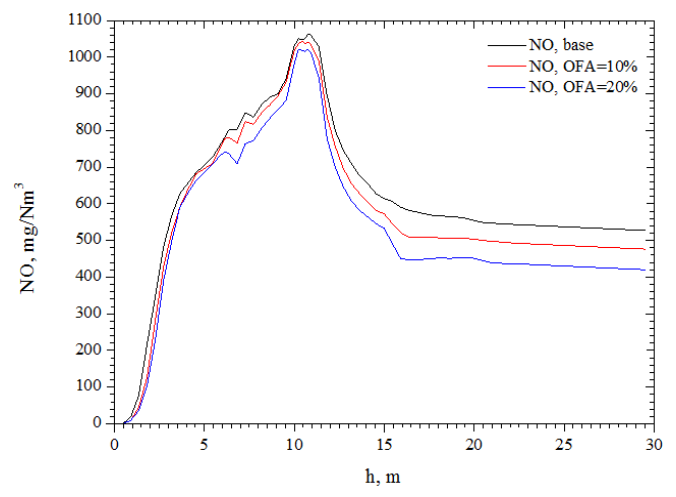

Fig.5. Distribution of NOx concentration along the furnace chamber height for different values of air supplied through the nozzles OFA

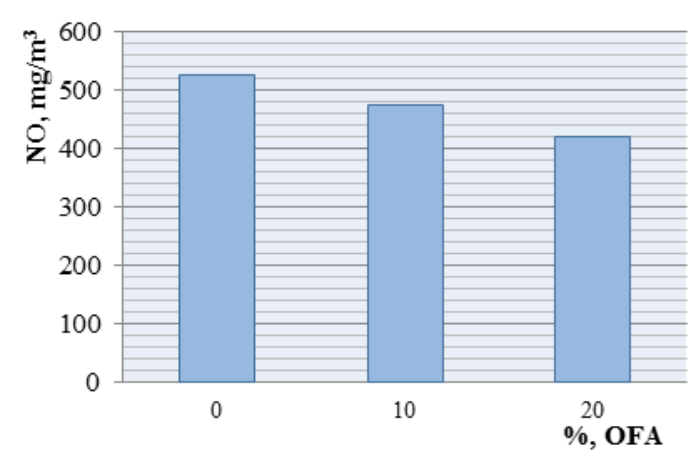

Fig.6. The effect of the percentage of mass air flow through the OFA injectors on the NO concentration at the outlet from the combustion chamber of the PK-39 boiler of the Aksu TPP

The increase in air supplied through the OFA injectors allows to reduce the concentration of nitric oxide at the outlet from the combustion chamber approximately on $20 \%$. The results of the studies are presented in the form of a diagram in Fig. 6. 


\section{CONCLUSION}

This paper presents the experiments on the implementation of the overfire air technology on the example of combustion chamber of PK-39 boiler of Aksu TPP. This technology is based on the separation of the oxidant supplied to the combustion chamber in such a way as to reduce the amount of fuel NOx in the burner location by reducing excess air, and reduce the amount of thermal NOx by reducing the temperature of the flame in the region of the location of the OFA-injectors.

Studies show that the implementation of OFA technology on the boiler PK-39 Aksu TPP leads to a change in the distribution of temperature $\mathrm{T}$, the concentrations of carbon $\mathrm{CO}_{2}$ and nitrogen $\mathrm{NO}$ oxides in the combustion chamber.

Thus, the studies in this paper demonstrate that overfire air technology is one of the most promising ways to reduce emissions of harmful substances (nitrogen oxide NOx and carbon dioxide $\mathrm{CO}_{2}$ ) in the atmosphere and can be used in the combustion of high-ash fuels in combustion chambers of coalfired TPPs.

\section{ACKNOWLEDGMENT}

This work was financially supported by the Ministry of Education and Science of the Republic of Kazakhstan - Grant №0115RK00599.

\section{NOMENCLATURE}

$u_{i}$ - components of the velocity, $\mathrm{m} / \mathrm{s}$;

$t$ - time, s;

$\rho$ - density, $\mathrm{kg} / \mathrm{m}^{3}$;

$\tau_{i j}-$ tensor of viscous tension;

$p$ - pressure, $\mathrm{Pa}$;

$f_{i}-$ volume forces, $\mathrm{N}$;

$h$ - enthalpy;

$q^{\text {res }}$ - energy flux density due to molecular heat transfer;

$S_{h}-$ a source of energy;

$c_{n}$ - mass concentration of the components of the substance;

$D_{c_{n}}$ - the diffusion coefficient of a component;

$S_{c_{n}}$ - the source term taking into account the contribution

of the chemical reactions in the change in the concentration of components;

$k$ - turbulent kinetic energy per unit mass;

$\mu_{\text {eff }}$ - effective viscosity;

$\sigma_{k}, \sigma_{\varepsilon}$ - turbulent Prandtl numbers - empirical constants in turbulence model;

$P$ - the production of turbulent kinetic energy, which is determined by the following equation;

$\varepsilon$ - dissipation rate of turbulent kinetic energy per unit mass;

$\delta_{i j}-$ Kronecker delta;

$\mu_{\text {turb }}$ - turbulent viscosity;

$c_{\varepsilon 1}, c_{\varepsilon 2}, c_{\mu}$ - empirical constants;

$v$ - frequency of radiant energy emitted from the element area;

$d s$ - length of the infinitesimal element allocated in space;
$K_{a b s}, K_{s c a}$ - optical absorption and scattering coefficients;

$\Omega$ - the solid angle;

$A i, B i$ - the coefficients in the Taylor series expansion functions of intensity of radiation;

$\sigma$ - Stefan-Boltzmann constant;

$b_{i j}$ - the matrix coefficient.

\section{REFERENCES}

[1] Askarova A., Bolegenova S., Bekmukhamet A., Maximov Yu.V., Beketayeva M., Ospanova Sh. Gabitova Z.K., "Investigation of turbulence characteristics of burning process of the solid fuel in BKZ 420 combustion chamber", WSEAS Transactions on Heat and Mass Transfer, Vol.9, 2014, pp. 39-50.

[2] Askarova A.S., Bekmukhamet A., Bolegenova S.A., Beketayeva M.T., Maximov Yu.V., Ospanova Sh.S., Gabitova Z.K., "Numerical modeling of turbulence characteristics of burning process of the solid fuel in BKZ-420-140-7c combustion chamber", International Journal of Mechanics, Vol.8, 2014, pp. 112-122.

[3] Askarova A.S., Bolegenova S.A., Maximov V.Y., Bekmukhamet A, Beketayeva M.T., Gabitova Z.K. et al. Computational method for investigation of solid fuel combustion in combustion chambers of a heat power plant, High temperature, Vol.53, No.5, 2015, pp.751-757.

[4] Askarova A., Bolegenova S., Bekmukhamet A., Ospanova Sh., Gabitova Z., "Using 3D modeling technology for investigation of conventional combustion mode of BKZ-420-140-7c combustion chamber", Journal of Engineering and Applied Sciences, Vol.9, No.1, 2014, pp. 24-28.

[5] Askarova A.S., Bolegenova S.A., Bekmuhamet A., Maximov V.Yu., "Mathematical simulation of pulverized coal in combustion chamber", Procedia Engineering, Vol.42, 2012, pp. 1259-1265.

[6] Askarova A., Bekmukhamet A., Bolegenova S., Ospanova Sh., Bolegenova Symbat, Maximov V. Beketayeva M., Gabitova Z., Ergalieva A., "3D modeling of heat and mass transfer during combustion of solid fuel in BKZ-420-140-7c combustion chamber of Kazakhstan", Journal of Applied Fluid Mechanics, Vol.9, No.2, 2016, pp. 699-709.

[7] Askarova, A.S., Lavrichsheva, Ye.I., Leithner, R., Müller, H., Magda, A., "Combustion of low-rank coals in furnaces of Kazakhstan coalfiring power plants". VDI Berichte, Vol.1988, 2007, pp. 497-502.

[8] Askarova, A. S., Vockrodt S., Leithner. et al., "Firing technique measures for increased efficiency and minimization of toxic emissions in Kasakh coal firing" VDI, 19th German Conference on Flames, Germany, VDI Gesell Energietechn; Verein Deutsch Ingn., Combustion And Incineration, VDI Berichte, Vol.1492, 1999, P. 93.

[9] Kuang M., Li Z., Liu C., Zhu Q., Zhang Y., Wang Y., "Evaluation of overfire air behavior for a down-fired 350 MWe utility boiler with multiple injection and multiple staging", Applied Thermal Engineering, Vol.48, 2012, pp. 164-175.

[10] Askarova A.S., Messerle V.E., Ustimenko A.B., Bolegenova S.A., Bolegenova S.A., Maximov V.Y., Ergalieva A., "Reduction of noxious substance emissions at the pulverized fuel combustion in the combustor of the BKZ-160 boiler of the Almaty heat electropower station using the "Overfire Air" technology", Thermophysics and aeromechanics, Vol.23, No.1, 2016, pp. 125-134.

[11] A.S. Askarova, E.I. Heierle, S.A. Bolegenova, V.Ju. Maximov, S.A. Bolegenova, R. Manatbayev, M.T. Beketaeva, A.B. Ergalieva, "CFD study of harmful substances production in coal-fired power plant of Kazakhstan", Bulgarian Chemical Communications, Special Issue E, 2016, pp. 260-265.

[12] Li M., Wang X., Sun S., Zhen X., Li Q., Zhang T., "Influence of Overfire air jet form on low NOx retrofit effect of an opposed firing boiler", Journal of Chinese society of power engineering, Vol.4, 2015, pp. 263-269.

[13] Askarova, A.S., Messerle, V.E., Ustimenko, A.B., Bolegenova, S.A., Maximov, V.Yu. Gabitova, Z.Kh., "Numerical simulation of pulverized coal combustion in a power boiler furnace", High temperature, Vol.53, No.3, 2015, pp. 445-452.

[14] Askarova, A.S., Bolegenova, S.A., Maximov, V.Y., Bekmukhamet, A, Beketayeva M., Gabitova Z., "Control of Harmful Emissions Concentration into the Atmosphere of Megacities of Kazakhstan 
Republic”, IERI Procedia, International Conference on Future Information Engineering (FIE2014), Beijing, 2014, pp. 252-258.

[15] A. Askarova, S. Bolegenova, S. Bolegenova, V. Maximov, R. Manatbayev, A. Yergaliyeva, Z. Gabitova, A. Maxutkhanova, Zh. Shortanbayeva, A. Boranbayeva, K. Berdikhan, "Application of 3D modelling for solving the problem of combustion coal-dust flame", Bulgarian Chemical Communications, Special Issue E, 2016, pp. 236241.

[16] R. Leithner, A. Askarova, S. Bolegenova, S. Bolegenova, V. Maximov, Sh. Ospanova, A. Ergalieva, A. Nugymanova, M. Beketayeva, "Computational modeling of heat and mass transfer processes in combustion chamber at power plant of Kazakhstan", MATEC Web of Conferences, 2016, $5 \mathrm{p}$.

[17] Askarova, A., Bolegenova, S., Bolegenova, S., Boranbayeva, A., Berdikhan, K., "Application of numerical methods for calculating the burning problems of coal-dust flame in real scale", International Journal of Applied Engineering Research, Vol.11, No.8, 2016, pp. 5511-5515.

[18] Askarova A., Bolegenova S. et al., "Influence of boundary conditions to heat and mass transfer processes", International Journal of Mechanics, Vol.10, 2016, pp. 320-325.

[19] Askarova A., Bolegenova S., Maximov V. et al., "On the effect of the temperature boundary conditions on the walls for the processes of heat and mass transfer", International Journal of Mechanics, Vol.10, 2016, pp. 349-355.

[20] Askarova, A. S., Bolegenova, S.A., Maximov, V.Y., Bekmukhamet, A, Ospanova, S.S., "Numerical research of aerodynamic characteristics of combustion chamber BKZ-75 mining thermal power station", Procedia Engineering, Vol.42, 2012, pp.1250-1259.

[21] Weber K., "Dreidimensionale Simulation der Gas-Festoff-Strömung in kohlegefeuerten Dampferzeugern", Fortschritt-Berichte VDI-Verlag, Vol.6, No.415, 1999, p. 198.

[22] Askarova A.S., Bolegenova S.A., Bolegenova S., Bekmukhamet A., Maximov V.Yu., Beketayeva M.T., "Numerical experimenting of combustion in the real boiler of CHP", International Journal of Mechanics, Vol.3, No.7, 2013, pp. 343-352.

[23] Askarova, A.S., Messerle, V.E., Ustimenko, A.B., Bolegenova, S.A., Maksimov, V.Yu., "Numerical simulation of the coal combustion process initiated by a plasma source", Thermophysics and aeromechanics, Vol.21, No.6, 2014, pp. 747-754.

[24] Aliyarov B.K., Aliyarova M.B. Szhiganie kazahstanskih ugley na TES $i$ na krupnyih kotelnyih: opyit i problemyi, Almatyi, 2012.

[25] Leithner R., Müller H., "CFD studies for boilers", Second M.I.T. Conference on Computational Fluid and Solid Mechanics, Cambridge, 2003, p. 172.

[26] Leithner R., Müller H., Heitmüller R., "Dreidimensionale Simulation von Dampferzeuger-Brennkammern einschließlich der NOxSchadstoffkinetik", VGB-Fachtagung: Dampfkessel und Dampfkesselbetrieb, Essen, 1993. 152 p.

[27] Müller H., "Numerische Berechnung dreidimensionaler turbulenter Strömungen in Dampferzeugern mit Wärmeübergang und chemischen Reactionen am Beispiel des SNCR-Verfahrens und der Kohleverbrennung", Fortschritt-Berichte VDI-Verlag, 1992, No.268, $158 \mathrm{p}$.

[28] Askarova, A.S., Karpenko, E.I., Karpenko, Yu.E., Messerle, V.E., Ustimenko, A.B., "Mathematical modelling of the processes of solid fuel ignition and combustion at combustors of the power boilers", 7th International Fall Seminar on Propellants, Explosives and Pyrotechnics. Xian, Vol.7, 2007, pp. 672-683.

[29] A.S. Askarova, S.A. Bolegenova, Symbat Bolegenova, V.Yu. Maximov, R. Manatbayev, Zh.K. Shortanbayeva, A.M. Maksutkhanova, A.N. Aldiyarova, A.E.Boranbayeva, "Mathematical modeling of heat and mass transfer in the presence of physicalchemical processes", Bulgarian Chemical Communications, Special Issue E, 2016, p. 272-277.

[30] Askarova, A.S., Maximov, V., Beketayeva, M., Safarik, P., 'Numerical Modeling of Pulverized Coal Combustion at Thermal Power Plant Boilers", Journal of thermal science, Vol. 24, No.3, 2015, pp. 275-282.

[31] Zeldovich J., "The oxidation of Nitrogen in combustions and explosions", Acta Physicochemica, Vol.21, 1946, pp. 557-628.

\section{BIOGRAPHIES}

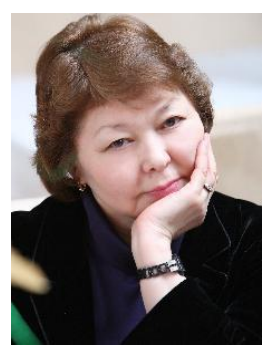

ALIYA ASKAROVA (Doctor of Science in Physics and Mathematics, Professor) actively engaged in research work. In 1999, defended doctoral thesis on the topic "Convective heat and mass transfer in physically and chemically reacting media". Currently is qualified in the field of thermal physics, engaged in mathematical and computer modeling of convective heat and mass transfer processes in physically and chemically reacting media, associated with combustion of gaseous and solid fuels and environmental issues of power system.

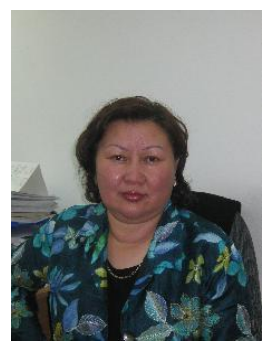

SALTANAT BOLEGENOVA (Doctor of Science in Physics and Mathematics, Professor) in 2003 defended her thesis on "Numerical study of chemically reacting turbulent gas jets in the presence of external influences". In 2010 she defended her doctoral thesis on the topic "Modeling of turbulent heat and mass transfer in high-temperature and chemically reacting streams". Scientific interests: heat and mass transfer, turbulence, modeling, fuel combustion.

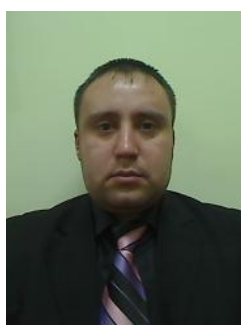

VALERIY MAXIMOV (PhD) in 2013 completed his doctoral studies in the specialty "Technical Physics" and defended his thesis on the topic "Investigation of thermal processes and aerodynamic characteristics of coal-fired power plants". Scientific interests: mathematical and computer simulation of the combustion of pulverized coal in the combustion chambers of thermal power plants.

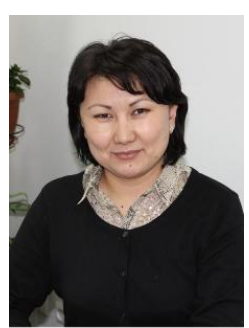

SYMBAT BOLEGENOVA (PhD) in 2012 defended thesis "Modelling the physico-chemical processes occurring during combustion of pulverized coal". Scientific interests: modeling of convective heat and mass transfer processes in reacting media.

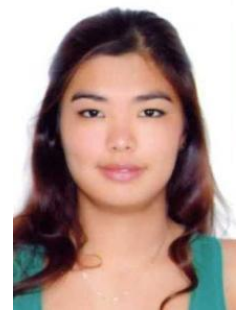

ZARINA GABITOVA (PhD) in 2016 defended thesis "Simulation of heat and mass processes in combustion chamber of TPP". Scientific interests: computer simulation of the combustion of pulverized coal in the combustion chambers, reduction of emissions of harmful substances in the atmosphere. 


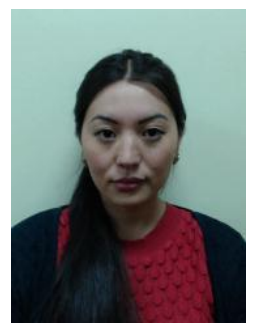

AIGUL YERGALIYEVA is a 3rd year PhD student at al-Farabi Kazakh National University. Scientific interests: heat and mass transfer, turbulent reacting flows, simulation, fuel combustion.

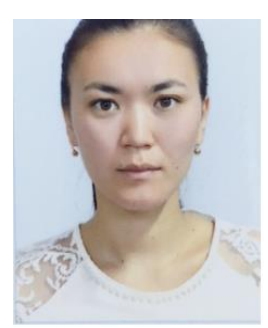

AIZHAN NUGYMANOVA is a 1 st year PhD student at al-Farabi Kazakh National University. Scientific interests: heat and mass transfer processes in combustion chambers, reduction of emissions of harmful substances.

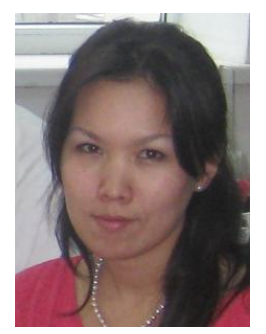

MERUERT BEKETAYEVA (PhD) in 2015 defended thesis "Three-dimensional modeling of the combustion of low-grade Kazakhstan coal in combustion chambers of thermal power plants". Scientific interests: mathematical simulation of the combustion of pulverized coal at thermal power plants.

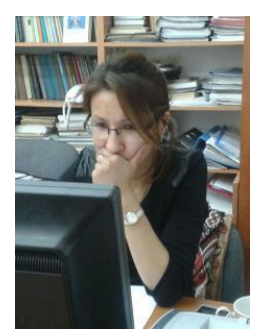

SHYNAR OSPANOVA $(\mathrm{PhD})$. Scientific interests: study of free jets of gas and liquid at acoustic exposures; study of threedimensional turbulent jets of gas and liquids; study of heat and mass transfer processes in physical and chemical reactive environments; combustion physics; statistical modeling of breakup, dispersion and evaporation of liquid drops in high turbulence. 